\title{
PHASE CHANGE OPTICAL STORAGE - A CRITICAL ASSESSMENT
}

\author{
(Invited)
}

\author{
K.A. RUBIN \\ IBM Research Division, Almaden Research Center, MS K67/802, 650 Harry Road, San Jose Ca. 95120, USA
}

\begin{abstract}
Recently there has been renewed interest in phase transformation based optical storage technology. Included among the many reasons for this interest has been the achievement of: (1) fast erase in conjunction with data stability, (2) demonstration of direct overwrite with good erasability, and in the last couple of years, (3) good progress in increasing the cyclability of the media. Direct overwrite has been demonstrated at media speeds from 1.25 to $22 \mathrm{~m} / \mathrm{s}$. More than $2 \times 10^{6}$ cycles have been achieved with low BER. In addition, phase change media exhibits strong signal response at wavelengths shorter than $830 \mathrm{~nm}$ and requires a much simpler optical head. In this paper we review past progress and assess the current status.

KEYWORDS: PHASE CHANGE, DIRECT OVERWRITE, PHASE TRANSFORMATION, OPTICAL STORAGE
\end{abstract}

\section{INTRODUCTION}

Phase change optical storage is attractive for removable optical storage devices. Media improvements have resulted in increased number of cycles with low BER, adequate erasability, writing sensitivity, and long lifetime. These improvements, coupled with the desire to use shorter wavelengths of light and simpler optics has led to continued interest. Research on understanding and improving the technology, with particular emphasis on the media, are reviewed in this paper.

Phase change materials have two stable structural states which are usually amorphous and crystalline. The different optical properties of the states allows data to be detected as modulations of reflected light intensities. A third, liquid, state is required for transforming from the crystalline to the amorphous state during writing. After a spot is melted it forms into an amorphous state if cooling occurs faster than the critical quench rate $(\mathrm{CQR})$ of the recording layer composition[1]. Erasure is accomplished by crystallizing the amorphous marks. A number of criteria, including fast crystallization, reliable cycling, stability against crystallization and chemical degradation, and adequate SNR, must be satisfied by the media[2],[3].

The concept of erasable phase change optical storage is more than 20 years old[4]. Early studies involved static cycling of tellurium-based alloys[5]. Progress continued with $4 \times 10^{4}$ static cycles reported in 1983[6]. Achievement of 106 cycles on a disk with 55db CNR using a tellurium-oxide based recording layer was also announced in 1983[7]. This media required $1 \mu \mathrm{s}$ to crystallize which necessitated a complicated two-beam optical head combining an elliptical erase with a circular write beam. Although this media was not stable, the announcement stimulated renewed research on phase change technology. Stable media exhibiting $>106$ static cycles was demonstrated in 1984 using TeGeSn alloys[8][9]. However, these compositions erased too slowly. In 1985, it was shown that stoichiometric compounds exhibited crystallization times of $<30 \mathrm{nsec}$ with long term data stability[10]. This allowed use of a much simpler to align, single-laser-beam optical head. Direct overwrite was demonstrated in 1986[11]. Media combining stability, $>2 \times 10^{6}$ cycles and direct overwrite was reported in 1989[12]. An erasable phase change drive was announced and began delivering in 1990[13]. Improvements in performance and understanding are continuing.

Phase change media shares attributes with other optical storage media but differs in some key areas. Plastic substrates are commonly used since grooves for tracking and header information for sector identification are easily molded. Most light is absorbed in the recording layer. The high temperatures of $>1000^{\circ} \mathrm{C}$ which the recording layer can reach during writing can damage the substrate so a thermal insulation dielectric layer is placed between them. This causes more heat to spread laterally into the overcoat where it is rapidly dissipated. An overcoat on the recording layer prevents movement while it is molten. The overcoat often consists both of a metal and dielectric layer. These are designed to give optimum cooling rate without sacrificing writing sensitivity. Writing sensitivity is improved by incompletely insulating the recording layer from the metal layer and designing the multilayer structure so both states have low reflectivity consistent with high contrast. The dielectric layer also prevents interdiffusion between the metal and recording layers.

\section{CRYSTALLIZATION AND AMORPHIZATION}

Fast crystallization is required from the media since the dwell time under the focused circular shaped laser spot is typically $<100 \mathrm{nsec}$. The crystallization time is predominantly determined by the recording layer composition. A large number of fast materials have been found. These include $\mathrm{GeTe}[10]$, $\mathrm{Sb}_{2} \mathrm{Te}_{3}[14]$ and compositions along the pseudo-binary $\mathrm{GeTe}-\mathrm{Sb}_{2} \mathrm{Te}_{3}$ tieline such as $\mathrm{Ge}_{2} \mathrm{Sb}_{2} \mathrm{Te}_{5}$, $\mathrm{GeSb}_{2} \mathrm{Te}_{4}$, and $\mathrm{GeSb}_{4} \mathrm{Te}$. Another group of fast materials crystallizes into a state which has lower reflectivity than the amorphous state. These include $\mathrm{In}_{3} \mathrm{SbTe}_{2}[15]$, compositions along the $\mathrm{InSb}-\mathrm{GaSb}$ tieline[3], and InSeTI[11]. The general criterion for selecting fast crystallizing media is to choose compositions which are at or near single phase stoichiometric regions of the phase diagram [10] or that crystallize into single phase metastable structures[3]. The fast crystallization results from the partitionless nature of 
the amorphous to crystalline transformation. Many systems exhibit wider range of single phase formation than predictions based solely on phase diagram considerations would suggest[2]. The composition range which form single phase compounds is extended by formation of metastable supersaturated phases[16]. Entirely new metastable compounds can form due to fast laser induced crystallization[17].

The presence of a metal layer can enhance the ability to amorphize media which has short crystallization times. For example, the compound GeTe could not be amorphized until a 50nm Al layer was added on top of the dielectric overcoat[10]. The cooling rate of $30 \mathrm{~K} / \mathrm{nsec}$ for the structure $150 \mathrm{~nm} \mathrm{SiO} \mathrm{x} / 75 \mathrm{~nm}$ $\mathrm{Ge}_{8} \mathrm{Te}_{6} \mathrm{Sn}_{16} / 150 \mathrm{~nm} \mathrm{SiO}_{\mathrm{x}} /$ polycarbonate disk was too low so crystallization occurred during cooldown[18]. It was increased to $\sim 10 \mathrm{oK} / \mathrm{nsec}$, allowing amorphization, by adding an $\mathrm{Al}$ layer. However, writing sensitivity suffered since the high thermal conductivity increased heat removal from the recording layer during the laser pulse.

The cooling rate of the structure is also determined by the thermal properties of the dielectric. This was illustrated by comparing the recording performance of the structure: $60 \mathrm{~nm}$ Diel / $100 \mathrm{~nm}$ Au / 70nm Diel / 30nm In22Sb37Te41 / 70nm Diel / Glass in which Diel indicates $\mathrm{SiN}_{\mathrm{x}}$ or yittria stabilized zirconia[19]. The thickness of the layers were optimized to give good writing sensitivity and readback contrast. The sensitivity of the disk with yittria stabilized zirconia was greater. However, the maximum CNR, which was only $40 \mathrm{db}$, was only achieved for a narrow power margin. In contrast, the disk with $\mathrm{SiN}_{\mathrm{X}}$ showed $50 \mathrm{db}$ CNR for a wide range of powers. These results were correlated with thermal modeling which suggested that the cooling rate of the disk using $\mathrm{SiN}_{\mathrm{x}} \mathrm{ex}$ ceeded the $\mathrm{CQR}$ of $50 \mathrm{~K} / \mathrm{nsec}$ for all laser powers from threshold to $>17 \mathrm{~mW}$. In contrast, the disk containing yittria stabilized zirconia exceeded the CQR only with powers in the narrow range of $9-12 \mathrm{~mW}$.

The required $C Q R$ can be reduced by changing the chemical composition of the recording layer. For example, adding 15 at\% $\mathrm{Sn}$ to GeTe increased the crystallization time sufficiently to preclude the need ror the Al layer[2]. This is useful for applications not requiring fast media speed.

The laser pulse width and power conditions which cause crystallization, amorphization and material failure depend upon the details of the media structure. These include the composition, thickness and method of preparation of the recording, dielectric and metal layers. A Phase Transformation Kinetics plot shows the laser pulse conditions which cause the transformations to occur[1]. It allows the kinetics and sensitivity of media to be compared quantitatively.

\section{DIRECT OVERWRITE - ERASING AND WRITING SIMULTANEOUSLY}

Direct overwrite eliminates an entire rotation of the disk which otherwise is required to erase the disk before writing new data. This effectively doubles the writing data rate if write verification is not needed. It is implemented by properly designing the thermal characteristics of the thin film structure, selecting a recording layer composition with the desired crystallization time and correctly controlling the laser power and pulse duration. Generally, a continuous intermediate bias laser power erases old data while a higher power is used for writing new data. Erasability, which measures the ability to remove old data is the difference between the carrier level of the new and old tone data. A summary of recent direct overwrite results is shown in Table 1.

Early experiments resulted in $46 \mathrm{db} \mathrm{CNR}$ and $14 \mathrm{db}$ erasability with the structure: $100 \mathrm{~nm} \mathrm{ZrO}_{2} / \mathrm{In}$ $\mathrm{SeTl} / 100 \mathrm{~nm} \mathrm{ZrO}_{2} / 2 \mathrm{P} /$ glass[11]. However, most data has been obtained using GeSbTe recording layer compositions. Variations of the composition and structure have allowed direct overwrite to be demonstrated with media speeds of $1.25 \mathrm{~m} / \mathrm{s}$ to $22 \mathrm{~m} / \mathrm{s}$. At $22 \mathrm{~m} / \mathrm{s}$, the structure: $20 \mathrm{~nm} \mathrm{Au} / 200 \mathrm{~nm} \mathrm{ZnS} / 60 \mathrm{~nm}$ GeSb2 Te4 / 100nm ZnS / polycarbonate disk exhibited 50db CNR with $23 \mathrm{db}$ erasability [21]. Changing from $\mathrm{ZnS}-\mathrm{SiO}_{2}$ to an $\mathrm{AlN}$ dielectric increased the erasability from 23 to $30 \mathrm{db}[22]$. The increased erasability was attributed to the higher thermal conductivity of the AlN. Other compositions containing GeSbTe also exhibit good performance. For example, a structure containing GeSbTeTlAg exhibited $60 \mathrm{db}$ CNR with $30 \mathrm{db}$ erasability[23]. GeSbTeCo gave $54 \mathrm{db}$ CNR with $30 \mathrm{db}$ erasability. However, the cycling performance of these more complex compositions have not been developed as much as those based solely on ternary GeSbTe compositions.

CD-ROM format requires writing very high data densities using PWM at low media speeds of $1.25 \mathrm{~m} / \mathrm{s}$. The relatively slow crystallizing, nonstoichiometric composition $\mathrm{Ge}_{12} \mathrm{Sb}_{39} \mathrm{Te} 49$, sandwiched between $\mathrm{SiO}_{2}-\mathrm{ZnS}$ dielectric layers yielded $>50 \mathrm{db}$ CNR[24]. The long dwell times of $0.7 \mathrm{us}$ caused tear drop shaped domains which resulted in undesired low erasability. The teardrops, presumably due to a gradual temperature increase of the surrounding region during the writing pulse, were eliminated by writing with a series of short pulses. The narrower width of the written domain allowed the erasability to be increased from $30 \mathrm{db}$ to $40 \mathrm{db}$. An added advantage is that the multiple pulse writing method was compatible with PWM.

In many cases, the jitter is better than the erasability would suggest. For example, using $10 \mathrm{~mW}$ and $7 \mathrm{~mW}$ erase bias powers on a disk with a GeTeSb based recording layer resulted in erasabilitys of $32 \mathrm{db}$ and $12.5 \mathrm{db}$, respectively[25]. However, the jitter was $17 \mathrm{nsec}$ for both cases. When new amorphous spots were formed, TEM analysis showed that a region around the newly formed spot was crystallized. While some of the previous tone data remained, causing the poor erasability, it was not detected as part of the signal from the new spot.

The highest erasability reported to date was achieved with the structure $100 \mathrm{~nm}$ AlN / $100 \mathrm{~nm} \mathrm{Au} /$ 70nm AlN / 30nm In22Sb37Te41 / 70nm AlN / 


\begin{tabular}{|c|c|c|c|c|c|c|}
\hline Media & $\begin{array}{l}\text { Media } \\
\text { Speed } \\
{[\mathrm{m} / \mathrm{s}]}\end{array}$ & $\begin{array}{l}\text { Write } \\
\text { Power } \\
\text { [mW] }\end{array}$ & $\begin{array}{l}\text { Bias } \\
\text { Power } \\
\text { [mW] }\end{array}$ & $\begin{array}{l}\text { CNR } \\
\text { [db] }\end{array}$ & $\begin{array}{l}\text { Erasa- } \\
\text { bility } \\
\text { [db] }\end{array}$ & $\begin{array}{l}\text { \# of } \\
\text { Cycles }\end{array}$ \\
\hline $\begin{array}{l}\text { 100nm Au / 70nm SiNx / 30nm In22Sb37Te41 / } \\
\text { 70nm } \mathrm{SiN}_{x} / \text { grooved glass [19] } \\
\text { 100nm ZrO2 / InSeTl / 100nm ZrO / 2P [20] }\end{array}$ & $\begin{array}{l}7.5 \\
11\end{array}$ & 14 & 10 & 46 & $\begin{array}{l}42 \\
14\end{array}$ & $\begin{array}{c}- \\
>100\end{array}$ \\
\hline $\begin{array}{l}\text { 140nm ZnS / 75nm (GeTe) }{ }_{85} \mathrm{Sn}_{15} / \\
140 \mathrm{~nm} \mathrm{ZnS} / \mathrm{PC}[2]\end{array}$ & 3 & 10 & 1 & 50 & 23 & - \\
\hline 80nm Au / 250nm SiN / 90nm GeSbTeTIAg / & 5.6 & 18 & - & 58 & 30 & 104 \\
\hline $\begin{array}{l}\mathrm{Ge}-\mathrm{Sb}-\mathrm{Te}-\mathrm{Co}[23] \\
\mathrm{Sn}-\mathrm{Sb}-\mathrm{Te}[23]\end{array}$ & 6.9 & 18 & - & $\begin{array}{l}54 \\
43\end{array}$ & $\begin{array}{l}30 \\
22\end{array}$ & $\begin{array}{l}>105 \\
2 \times 10^{4}\end{array}$ \\
\hline $\begin{array}{l}50 \mathrm{~nm} \text { Au / } 12 \mathrm{~nm} \mathrm{ZnS}-\mathrm{SiO} 2 / \\
20 \mathrm{~nm} \mathrm{Ge}_{12} \mathrm{Sb}_{39} \mathrm{Te}_{49} / 150 \mathrm{~nm} \mathrm{ZnS} \mathrm{SiO}_{2}[24]\end{array}$ & 1.25 & 12 & 6.2 & $\begin{array}{l}57 \\
55\end{array}$ & $\begin{array}{l}28(c) \\
40(d)\end{array}$ & $>100$ \\
\hline $\begin{array}{l}\text { 100nm Al-alloy / 30nm } \mathrm{ZnS}-\mathrm{SiO}_{2} / \\
(\mathrm{GeTe})_{2}\left(\mathrm{Sb}_{2} \mathrm{Te}_{3}\right) \mathrm{Sb}_{1.5} / 6 \mathrm{~nm} \mathrm{ZnS}-\mathrm{SiO}_{2} / \mathrm{PC}[22]\end{array}$ & 8 & 16 & 6 & 51 & 22 & - \\
\hline $40 \mathrm{~nm} \mathrm{Al} / 35 \mathrm{~nm} \mathrm{SiO} 2-\mathrm{ZnS} / 80 \mathrm{~nm} \mathrm{Ge}-\mathrm{Te}-\mathrm{Sb} /$ & 8 & 16 & 7 & 49 & 27 & $3 \times 10^{4}(\mathrm{a})$ \\
\hline $\begin{array}{l}\text { 254nm SiO2-ZnS / PC [35] } \\
\text { 100nm Al-alloy / 30nm ÂIN } \\
\text { (GeTe)2(Sb2Te3)Sb1.5/16nm ZnS-SiO2/PC[22] }\end{array}$ & 8 & $\begin{array}{l}18 \\
20\end{array}$ & 10 & 50 & 30 & $\begin{array}{c}>10^{6}(\mathrm{~b}) \\
>106\end{array}$ \\
\hline $\begin{array}{l}\mathrm{NiCr} / \mathrm{SiO}-\mathrm{ZnS} / \mathrm{Te}_{52.5} \mathrm{Ge}_{15.3} \mathrm{Sb}_{33} / \\
\mathrm{SiO} 2-\mathrm{ZnS} / \mathrm{PC}[12]\end{array}$ & 9 & 13 & 7 & 50 & 23 & $>2 \times 10^{6}$ \\
\hline $\begin{array}{l}20 \mathrm{~nm} \mathrm{Au} / 200 \mathrm{~nm} \mathrm{ZnS} / 60 \mathrm{~nm}_{\mathrm{GeSb}} \mathrm{Te}_{4} / \\
100 \mathrm{~nm} \mathrm{ZnS} / \mathrm{PC}[21]\end{array}$ & 22 & 22 & 10 & 51 & 20 & $>10^{5}$ \\
\hline
\end{tabular}

Table 1. Writing and erasing performance of selected media and structures using direct overwrite. CNR is in $30 \mathrm{kHz}$ bandwidth. The table is subdivided into classes of recording media compositions and ordered in terms of media speed within those subclasses. References are indicated by numbers in brackets. PC indicates polycarbonate disk substrate. 2P indicates 2P / glass substrate. Notes: (a) Conventional cycling. (b) Mark-shift cycling. (c) Conventional writing. (d) Multipulse writing.

grooved glass[26]. The good erasability was associated with using high erase bias powers to melt the recording layer. Similar good erasability was observed using $\mathrm{SiN}_{\mathrm{x}}$ instead of AlN for the dielectric layers[19].

\section{MEDIA STABILITY}

Phase change media must be stable against degradation by crystallization or chemical reaction. The stability of the amorphous state is enhanced by picking materials with high crystallization temperatures, since the crystallization temperature is typically half the melting temperature[3]. Long term stability of the amorphous state suggests that the crystallization temperature be $>1500^{\circ C}$ when heated at $\sim 10 \circ \mathrm{C} / \mathrm{min}$. However, higher melting temperature materials are not desired since more laser power is required for writing and the number of cycles generally is decreased.

Experiments which examine the stability of amorphous as-deposited media versus elevated temperature are useful, but generally overestimate the lifetime of laser amorphized spots. For example, the crystallization temperature of laser amorphized $\mathrm{Ge}_{\mathrm{x}} \mathrm{Te}_{1-\mathrm{x}}$ compositions is $\sim 20$ oC lower than as-deposited films[27]. This may arise from the presence of residual crystalline nuclei in the amorphous spot or the amorphous/crystal boundary may nucleation sites. The crystallization properties of amorphous as- deposited $\mathrm{Ge}_{\mathrm{x}} \mathrm{Te} 1-\mathrm{x}$ system were studied using reflectivity to measure of fraction crystallized[28]. It correlated reasonably well with DSC measurements. The activation energy for crystallization rose monotonically with increased Ge concentration. However a large unexplained jump from $1.2 \mathrm{eV}$ to more than $3 \mathrm{eV}$ occurred in the vicinity of the compound GeTe.

The stability of amorphous marks of GeSbTe was examined using optical and microstructural observations [29]. Following a method similar to van der Poel[30], the Johnson-Mehl-Avrami equation was used to analyze crystallization induced by multiple laser passes. The volume fraction crystallized was assumed proportional to the reflectivity change. Though the spots were heated and cooled multiple times, the analysis assumed isothermal heating. The validity of these assumptions was not determined. An activation energy of $E_{a}=2.42 \mathrm{eV}$ was obtained. The amorphous spots were estimated to be stable for 96 years at $50 \circ \mathrm{C}$.

Accelerated aging studies of the structure: $\mathrm{Al}$ alloy / 20nm ZnS-SiO2 / (GeTe)2(Sb2 $\left.\mathrm{Te}_{3}\right)_{1} \mathrm{Sb}_{2} .5 /$ $150 \mathrm{~nm} \mathrm{ZnS}-\mathrm{SiO}_{2} /$ polycarbonate showed that the BER did not double until after 2000 hours at $80{ }^{\circ} \mathrm{C}$, $80 \% \mathrm{RH}[31]$. An activation energy of $1.1 \mathrm{eV}$ and lifetime of 60 years was obtained for the BER to double at $32 \circ \mathrm{C}$ and $80 \% \mathrm{RH}$. The mechanism associated with the increase was not determined. 


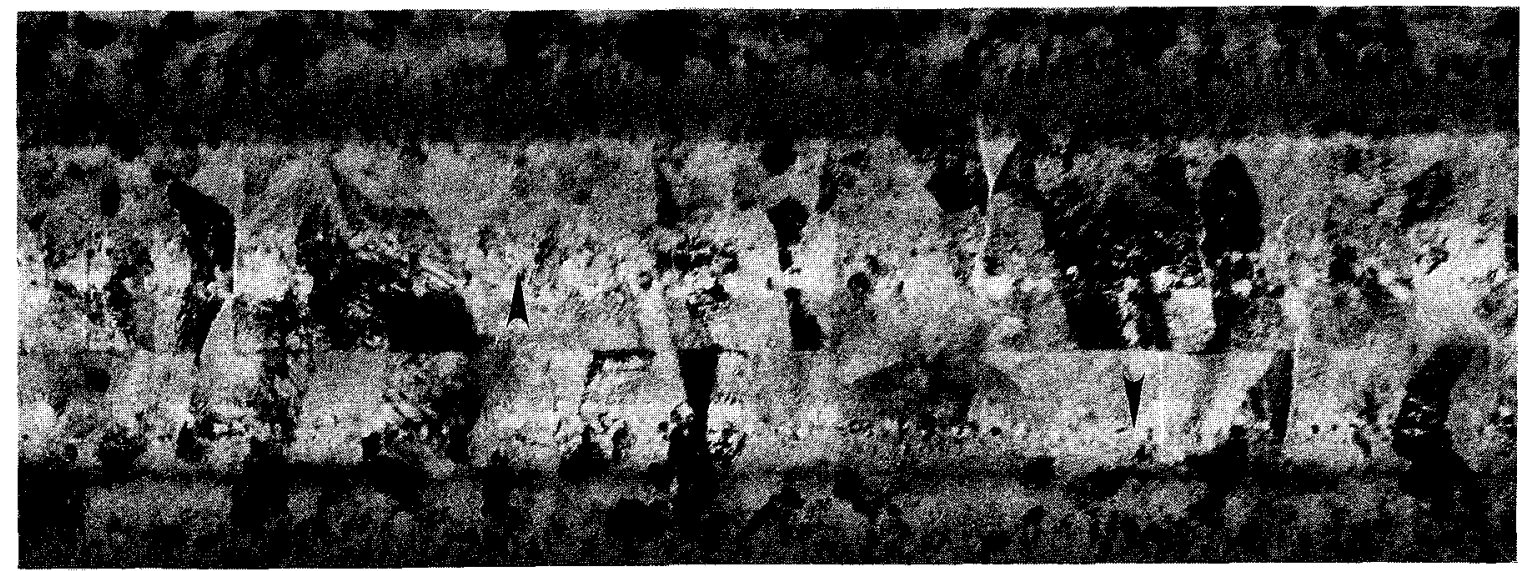

Figure 1. TEM micrograph of a track of (GeTe) $85 \mathrm{Sn} 15$ sandwiched by 7059 glass which was erased 100 times. A couple of the phase separated regions are indicated by arrows.

\section{REVERSIBLE CYCLING}

Efforts to increase the number of cycles have resulted in continued improvement although more understanding of what limits the number of cycles is needed. In applications such as libraries, 100 cycles may be adequate. Directory areas, which are written many times, will need many more cycles.

Systematic study of the cycling of (GeTe) ${ }_{85} \mathrm{Sn}_{15}$ showed that failure occurred when either too much or too little laser power was applied[32]. Microstructure analysis showed that at high powers defects such as voids are formed in the recording layer. At low powers, the size of the amorphous spot gradually becomes smaller, resulting in lost contrast. This was attributed to phase separation. Phase separation has been observed with compositions which crystallize into metastable structures. An example of the resulting microstructure is illustrated in Figure 1.

The cycling of stoichiometric In3SbTe2 and nonstoichiometric $\mathrm{In}_{22} \mathrm{Sb}_{37} \mathrm{Te}_{41}$ recording layers were compared[33]. Using In $22 \mathrm{Sb}_{37} \mathrm{Te}_{41}$, resulted in poor cycling performance as indicated by the rapid increase in BER after 1000 cycles. TEM analysis of a disk which had been cycled 2000 times showed that significant phase separation occurred within the recording layer. However, more than 105 cycles were observed without any indications of failure when cycling the structure $100 \mathrm{~nm} \mathrm{Au} / 70 \mathrm{~nm} \mathrm{ZnS} \mathrm{/} \mathrm{30nm}$ $\mathrm{In}_{3} \mathrm{SbTe}_{2} / 70 \mathrm{~nm} \mathrm{ZnS} /$ grooved glass. While unlikely, the different dielectric compositions may have affected the degree of segregation.

Reducing the recording layer thickness from $80 \mathrm{~nm}$ to $20 \mathrm{~nm}$ increased the number of cycles from 104 to 106 cycles[12]. The increased cycles were associated with elimination of pinhole generation. The greatest number of direct overwrite cycles reported to date are $2 \times 10^{6}[31]$. A SiO $2-\mathrm{ZnS}$ mixed dielectric surrounded the recording layer of $\mathrm{GeTe}-\mathrm{Sb}_{2} \mathrm{Te}_{3}-\mathrm{Sb}$. The CNR and reflectivity decreased and increased, respectively, as cycling continued. However, the BER and erasability were constant throughout the cycling. The optical changes were consistent with a fail- ure model based on lateral flow induced thinning. Microstructure analysis may provide further insight into the failure mechanism.

The conditions used for depositing the overcoat are strongly correlated with the number of cycles. For example, the number of direct overwrite cycles varied from $3 \times 10^{3}$ to $5 \times 10^{5}$ using $\mathrm{Si}_{3} \mathrm{~N}_{4}$ overcoat deposited with Ar gas pressures of 1.0 to $0.2 \mathrm{~Pa}$ [34]. STM analysis of the overcoat showed that the larger number of cycles occurred with smoother coatings associated with decreased Ar pressure. Measurement of the variation of the writing sensitivity suggested that the film density decreased with increased roughness. While the degradation mechanism associated with cycling failure was not determined, it is possible that the $90 \mathrm{~nm} \mathrm{Si3} \mathrm{N}_{4}$ subbing layer was too thin to prevent excessive heat from reaching the substrate.

Good cycling has also been obtained with thicker recording layers by using a defect management scheme where the position of the written spot was varied every time a sector is written[35]. The defects had been preferentially occurring at the beginning of a sector where the clock was synchronized with the ROM sector id bits causing spots to be written repetitively at the same locations. Further along the sector, the spots were written in random locations and defects occurred less often. The defects caused the jitter to increase monotonically when conventional recording was used, yielding less than $10^{5} \mathrm{cy}$ cles. By shifting the position where writing started, the jitter was constant for more than $10^{6}$ cycles. Another way to deal with limited number of cycles is to relocate bad sectors[36].

\section{SIGNAL TO NOISE RATIO}

The ability to reliably detect data is improved with increased SNR. The readback signal to noise ratio is determined by the reflectivity difference between the amorphous and crystalline state and by media noise. The signal from phase change media is very strong - approximately 1000 times that of magnetooptic media. The signal cannot be increased much 
since materials such as GeTe already have reflectivities of $\sim 40 \%$ and $\sim 70 \%$, in the amorphous and crystalline states respectively. Optical tuning using interference layers could result in reflectivities of $10 \%$ and $90 \%$, respectively. However, the high reflectivity would significantly impact the writing sensitivity and so are not desired.

Theoretically the high signal suggests that a shot noise limited $60 \mathrm{db}$ is possible compared to the $25 \mathrm{db}$ commonly achieved today with $1 \mathrm{~mW}$ readback intensity. However, the SNR is currently limited by media noise. Currently, the sources of media noise are: tracking grooves in the substrates, (2) crystalline grain noise, (3) as-deposited film noise, and (4) writing noise [3]. Groove noise can be reduced by improving the the mastering process. Alternatively, using sector servo would allow the grooves to be eliminated. The substrate noise would then be limited by the ability to polish the master. One way to reduce media noise is to use recording layer compositions which crystallize into a cubic structure[2]. The orientation of the crystallites is irrelevant since the optical reflectivity is isotropic. The majority of erasable phase change media which are under development crystallize into a cubic structure. As-deposited film noise arises from the statistical nature in which atoms are transported and stick to the substrate during vacuum deposition. Alternatively, smarter data detection techniques may help increase the SNR.

\section{DATA DENSITY}

The areal density of recorded data increases as (N.A. $\lambda)^{2}$ where N.A. and $\lambda$ are the numerical aperture of the objective lens and wavelength of light, respectively. Typical lens numerical apertures are between 0.50 and 0.7 . It may be possible to increase the N.A. slightly more. Recent developments in laser technology have provided higher power red semiconductor lasers and blue laser light by frequency doubling near-IR laser light [37].670nm lasers have been demonstrated with $80 \mathrm{~mW}$ of power. These will allow a density improvement of $50 \%$ compared to $830 \mathrm{~nm}$. $40 \mathrm{~mW}$ of laser power has been generated using $428 \mathrm{~nm}$ blue light which provides a potential of 4-fold data density increase if an acceptable media is available. Phase change media should be usable at shorter wavelengths. For example the reflectivity of the amorphous and crystalline state of GeTe are $43 \%$ and $69 \%$ at $450 \mathrm{~nm}$.

Use of PWM would allow higher recorded data density. However, with PWM, both the leading and trailing edge must be placed accurately to obtain low jitter. A comparison of data written using (2-7) codes at $8 \mathrm{~m} / \mathrm{s}$ with PWM and PPM methods showed that adequately low jitter was obtained[38]. However, it was important that a high cooling rate structure be used to obtain the low jitter.

Presently, the density is limited by the readback resolution, not the ability to write small amorphous marks. For example, $0.25 \mu \mathrm{m}$ diameter spots have been written at $0.5 \mu \mathrm{m}$ track pitch[38]. These were observed by optical microscopy. Similar sized small spots have been observed by TEM[32]. Even smaller domains than used today can be supported. For example, very small stable written domains have been formed in amorphous GeTe thin films. Scanning tunneling microscopy techniques were used both to crystallize and image 10nm diameter domains[39].

\section{DRIVE IMPLICATIONS}

The optical head of a phase change drive is very simple. There is no need to maintain the polarization state of the reflected light so less expensive optical components can be used. Also, no bias magnet is needed.

Phase change media can be used as one type of media for a multi-function drive. The reflectivity based readback method is identical to that of ROM and write-once media although the magnitude of the reflectivity of ROM is higher than erasable phase change media. For example, the compatibility of erasable phase change media in a WORM drive was demonstrated[40]. Data was written on write-once media by selectively crystallizing domains of increased reflectivity. In contrast, the written domains of erasable phase change media were formed by amorphizing regions of reduced reflectivity. Since the two signals had opposite polarity, an inverter was switched in between the readback preamp and the data channel so both types of media had the same polarity. This allowed a single channel to be used to detect data from both types of media.

An alternative application of phase change media is to use a laser and detector mounted on a slider to form a flying optical head. The lighter weight could provide access times comparable to those of magnetic Winchester drives. Unlike conventional optical heads which incorporate mirrors and lenses, it had neither. This would allow several platters of optical media to be closely stacked parallel to one another with a head between each platter, for increased storage capacity. A $1.13 \mu \mathrm{m}$ laser was integrated monolithically with a photodetector on a slider[41]. The slider flew $2 \mu \mathrm{m}$ from the front surface of a GeTeSb recording layer protected by a SiN thin coating. This head was simple compared to a flying magneto-optic head. Light reflected from the recording layer was detected by the photodiode for data readback. Sampled servo was used for tracking. Data was written at $1 \mathrm{MHz}$ with $2.4 \mu \mathrm{m}$ pitch. The laser operated successfully for more than $4 \times 10^{8}$ passes before failing. The authors proposed using shorter wavelength $0.83 \mu \mathrm{m}$ lasers if proper protective layers were developed.

\section{CONCLUSIONS}

Phase change technology continues to develop at a rapid pace. Many cycles of direct overwrite recording with low BER and long term stability have been demonstrated. Many of the compositions which have good recording and erasing performance crystallize into metastable crystalline phases. More understanding of their stability against phase separation after repetitive cycling is needed. The ternary material 
system $\mathrm{GeTeSb}$ is the most well developed. It can accommodate reversible recording at a wide range of data rates. The CNR is adequate and could potentially be significantly improved. Both PPM and PWM recording have been demonstrated with low jitter. Small spots of $0.25 \mu \mathrm{m}$ diameter such as required for blue laser recording have been written. The simple detection optics may allow the size of the optical head to be reduced. With the growing interest in the field there are bound to be many further developments in the science and technology of phase change reversible optical recording.

\section{ACKNOWLEDGEMENTS}

The author wishes to thank $M$. Chen and T. Suzuki for helpful discussions and T. Suzuki for TEM microstructure analysis.

\section{REFERENCES}

[1] K. A. Rubin, R. W. Barton, M. Chen, V. B. Jipson and D. Rugar, App. Phys. Lett., 50 (1987) 1488.

[2] M. Chen and K. A.Rubin, Proc.Soc. Photo-Opt.Inst. Eng., 1078 (1989), 150.

[3] K. A. Rubin and M. Chen, Thin Solid Films, 181 (1989) 129.

[4] S. R. Ovshinsky, J. Non-Cryst. Solids 2, (1970) 99.

[5] D. Strand and D. Adler, Proc. Soc. Photo-Opt. Inst. Eng. 420 (1983) 200

[6] P. C. Clemens, Appl. Opt. Lett. 22 (1983) 3165.

[7] M. Takenaga, N. Yamada, O. Phara, K. Nisiuchi, M. Nagashima, T. Kashihara, S. Nakamura and T. Yamashita, Proc. Soc. Photo-Opt. Inst. Eng. 420 (1983) 173.

[8] SPIE Top. Meet. Opt. Data Stor, Montery, Ca. (April 18, 1984).

[9] M. Chen, K. A. Rubin, V. Marrello, U. G. Gerber, and V. B. Jipson, Appl. Phys. Lett. 46 (8), (1985) 734.

[10] M. Chen, K. A. Rubin and R. Barton, App. Phys. Lett., 49 (1986) 1255.

[11] T. Nishida, M. Terao, Y. Miyauchi, S. Horigome, T. Kaku, and N. Ohta, App. Phys. Lett., 50 (1987) 667.

[12] T. Ohta, M. Uchida, K. Yoshioka, S. Furukawa and K. Kotera, Proc. Soc. Photo-Opt. Inst. Eng., 1078 (1989), 27.

[13] Model LF-7010 optical disk drive, mfd. by Matsushita Electric Industrial Co., Ltd., Osaka, Japan.

[14] N. Yamada, E. Ohno, N. Akahira, K. Nishiuchi, K. Nagata, and M. Takao, Jap J. App. Phys. 26 Supp 26-4 (1987) 61 .

[15] Y. Maeda, H. Andoh, I. Ikuta, and H. Minemura, J. Appl. Phys. 64 (4), (1988) 1715.

[16] M. Libera, M. Chen and K. A. Rubin, to appear in J. Mat. Res.

[17] R. Barton, C. R. Davis, K. Rubin and G. Lim, App. Phys. Lett., 48 (1986) 1255.

[18] M. Libera, M. Chan and K. A. Rubin, MRS Proc. 152, ed. by D. Poker, (1989).

[19] Y. Maeda, H. Minemura, M. Nagai, I. Ikuta and H. Andoh, Jap. J. App. Phys., 28 Suppl. 28-3 (1989) 147.

[20] M. Terao, T. Nishida, Y. Miyauchi, S. Horigome, T. Kaku and N. Ohta, Proc. Soc. Photo-Opt. Inst. Eng., 695 (1986), 105.

[21] N. Yamada, E. Ohno, N. Akahira, K. Nishiuchi, K. Nagata, and M. Takao, et al, Jap. J. App. Phys., 23, Suppl. 26-4 (1989) 61.

[22] T. Ohta, K. Inoue, M. Uchida, K. Yoshioka, T. Akiyama, S. Furukawa, K. Nagata and S. Nakamura, Jap.J. App. Phys, 28 Supl. 28-3 (1989) 123.
[23] M. Terao, Y. Miyauchi, K. Andoo, H. Yasuoka, R Tamura, Proc. Soc. Photo-Opt. Inst. Eng., 1078 (1989) 2. [24] E. Ohno, K. Nishiuchi, N. Yamada and N. Akahira, in Optical Data Storage, 1991, Tech. Dig. Ser., 5 (Opt. Soc. Amer.) 92.

[25] T. Ishida, S. Ohara, N. Akahira, T. Ohta and T. Yoshida, Jap. J. App. Phys, 28 Supp. 28-3 (1989) 129.

[26] Y. Maeda, H. Andoh, I. Ikuta, M. Nagai, Y. Katoh, H. Minemura, N. Tsuboi, Y. Satoh, N. Gotoh and M. Ishigaki, App. Phys. Lett., 54 (1989) 893.

[27] K. A. Rubin and Y. W. Chen, presented at Top. Meet. Opt. Data Stor., Wash., D.C., Oct. 1985.

[28] T. Matsushita, T. Nakau, A. Suzuki and M. Okuda, $J$. Non-Crys. Sol. 112 (1989), 211.

[29] K. Ozawa, S. Ogino, Y. Satoh, T. Urushidani, A. Ueda, H. Kawakami, in Optical Data Storage. 1991, Tech. Dig. Ser., 5 (Opt. Soc. Amer.) 96.

[30] C. J. van der Poel, D. J. Gravesteijn, W. G. V. M. Rippens, H. T. L. P. Stockx, and c. M. J. van Uijen, J. Appl. Phys. 59 (6), (1986) 1819.

[31] T. Ohta, S. Furukawa, K. Yoshioka, M. Uchida, K. Inoue, T. Akiyama, K. Nagata and S. Nakamura, Proc. Soc. PhotoOpt. Inst. Eng., 1316 (1990), 367.

[32] K. A. Rubin, T. Suzuki, and Y. W. Chen, pres. SPIE, Vancouver, Canada, April, 1990.

[33] Y. Sato, H. Minemura, Y. Maeda, I. Ikuta, H. Andoh, N. Tsuboi, and M. Nagai, Proc. Soc. Photo-Opt. Inst. Eng., 1316 (1990), 267.

[34] R. Chiba, H. Yamazaki, S. Yagi, and S. Fujimori, Appl. Phys. Lett. 56 (24), (1990) 2373.

[35] M. Suzuki, K. Furuya, K. Nishimura, K. Mori, and I. Morimoto, Proc. Soc. Photo-Opt. Inst. Eng., 1316 (1990), 375.

[36] S. Ohara et al, Proc. Soc. Photo-Opt. Inst. Eng., 1248 (1990), 74.

[37] W. Koslowski, W. Lenth, E.E. Latta, A. Moser, G. L. Bona, App. Phys. Lett., 56 (1990) 2291.

[38] Y. Miyauchi, M. Terao, K. Andoo, R. Tamura and N. Ohta, Jap. J. App. Phys, 28 Supp. 28-3 (1989) 141.

[39] J. S. Foster, K. A. Rubin, and D. Rugar, U. S. Patent $4,916,688$.

[40] S. Ohara, C. Inokuchi, T. Furutani, T. Ishida, K. Ishibashi, A. Kurahashi, and T. Yoshida, in Optical Data Storage. 1991, Tech. Dig. Ser., 5 (Opt. Soc. Amer) 100.

[41] H. Ukita, H. Nakada and Y. Katagiri, in Optical Data Storage. 1991, Tech. Dig Ser., 5 (Opt. Soc. Amer) 130. 